\title{
Sistema de AVALIAÇÃo PARA CLASSIFICAR ÁREAS DE DISPOSIÇÃo DE RESÍDUOS SÓLIDOS URBANOS VISANDO A REMEDIAÇÃO E A PÓS-OCUPAÇÃO
}

\section{EVALUATION SYSTEM FOR RATING URBAN SOLID WASTE DISPOSAL SITES FOR REMEDIATION AND POST OCCUPATION}

\author{
ADRIANA SOARES DE SCHUELER \\ D.Sc. em Engenharia Civil (Geotecnia Ambiental) - COPPE/UFRJ. Arquiteta. Pesquisadora de \\ Pós-Doutorado - COPPE/UFRJ
}

\section{CLÁUDIO FERNANDO MAHLER}

L.D. ESP/USP, D.Sc. em Engenharia Civil - COPPE/UFRJ. Professor associado da COPPE/UFRJ. Coordenador de Pós Graduação do CT/UFRJ

Recebido: 02/10/06 Aceito: 03/06/08

\section{RESUMO}

A disposição de resíduos sólidos urbanos em locais sem infra-estrutura de proteção ambiental pode ser responsável pela contaminação de recursos naturais e de seres humanos e animais por meio da emissão de efluentes líquidos e gasosos. A metodologia proposta visa contribuir com a avaliação do risco de exposição ao lixiviado, bem como sugerir procedimentos de monitoramento da área, de acordo com diferentes níveis de cuidado e urgência. O método baseia-se em quatro matrizes onde é possível ser feita uma avaliação inicial da fonte do risco, do sujeito potencialmente atingido, e dos caminhos ambientais superficiais e subterrâneos. Neste trabalho foi considerada, essencialmente, a contaminação causada por efluentes líquidos.

PALAVRAS-CHAVE: Sistema de classificação de aterros de resíduos urbanos, impacto ambiental, avaliação de risco, lixiviado, risco de exposição, monitoramento.

\begin{abstract}
Disposal of urban solid waste in sites without infrastructure for environmental protection may be responsible for contamination of natural resources and human beings by gas and liquid effluent emission. The proposed methodology aims to contribute in the evaluation of risk to the exposure to leachate as well as suggested procedures for site monitoring, according to different levels of care and urgency. The method is based on four matrices where it is possible to make an initial evaluation of the source of the risk, the potential target and the superficial and underground environmental paths. In this paper only the contamination caused by liquid effluents were considered.
\end{abstract}

KEYWORDS: Classification system, environmental impact, risk assessment, Leachate, risk of exposition, monitoring.

\section{INTRODUÇÃO}

A disposição de RSU (resíduos sólidos urbanos) em locais sem infraestrutura de proteção ao meio ambiente pode ser responsável pela contaminação do solo, águas e ar por meio da emissão de efluentes líquidos e gasosos. Mesmo após o encerramento das atividades de disposição, os resíduos e seus efluentes podem continuar contaminando o meio.

O gás é produzido a partir da biodegradação do material orgânico presente no resíduo e pode acumular-se criando bolsōes com risco de explosões por combustão no interior do aterro. Os principais gases identificados são os $\mathrm{CH}_{4}, \mathrm{CO}_{2}, \mathrm{CO}, \mathrm{H}_{2}, \mathrm{H}_{2} \mathrm{~S}, \mathrm{NH}_{3}, \mathrm{~N}_{2}$ e $\mathrm{O}_{2}$ presentes em grandes concentra- ções. Em condições normais a velocidade de decomposição, medida pela produção de gás, chega ao seu máximo nos primeiros dois anos. Depois disso, baixa lentamente, podendo os gases serem encontrados durante vinte a trinta anos, ou mais (Tchobanoglous, 1998).

O lixiviado é composto pela própria umidade do resíduo e pela umidade gerada no processo de biodegradação - neste trabalho identificados como chorume - somada a água que se infiltra através da superfície do aterro e extrai do resíduo material dissolvidos ou em suspensão.

No Brasil, existem em grande número, lixões desativados, escondidos sob camada de solo, sem maiores cuidados de proteção ambiental. Esses locais apresentam um passado normalmente misterioso, em que não se conhece o solo e o subsolo sob o aterro, o material ali disposto, e em muitos casos, nem mesmo o tempo de duração em que tal disposição ocorreu.

No presente trabalho é proposto um método para classificação de aterros de RSU em relação à avaliação do risco do lixiviado produzido atingir a população e os recursos naturais. Depois de classificado, são sugeridos procedimentos de monitoramento da área, de acordo com diferentes níveis de cuidado e urgência.

\section{METODOLOGIA}

Para a caracterização de um risco, são necessários a existência de uma 
fonte - o lixiviado produzido pelo aterro de lixo - e de um sujeito - o ser humano e os recursos naturais. Numa avaliação de risco deve ser identificado o perigo, a exposição, a avaliação propriamente e seu gerenciamento. (NRC, 1983 in Nardocci, 1999). A etapa da avaliação da exposição consiste, inicialmente, na:

- Identificação qualitativa do volume do contaminante - o lixiviado - potencialmente produzido num aterro de RSU, possível de contaminar o solo, as águas superficiais e subterrâneas e o ar;

- Identificação dos caminhos ambientais que o lixiviado pode seguir até alcançar o ser humano ou afetar recursos naturais;

- Identificação da mobilidade do lixiviado, que permite que a população ou os recursos naturais, fora dos limites da área de disposição dos resíduos sejam efetivamente alcançados.

O método proposto resultou na construção de quatro matrizes que, em conjunto, buscam orientar na etapa da avaliação do risco da exposição do ser humano e dos recursos naturais à contaminação por lixiviado de RSU.

O somatório dos valores obtidos nas matrizes permite alcançar uma pontuação que será utilizada como sinalizador da necessidade de intervençôes. Dependendo das características de geração do lixiviado, de sua capacidade de atingir o solo, as águas, as áreas de proteção ambiental e a população, são sugeridas intervenções com diferentes níveis de cuidado e urgência, e monitoramento após o fechamento.

Foram considerados parâmetros referentes a:

a) Fonte do contaminante: Volume potencial de chorume produzido, influenciado pelo volume do aterro e idade do último resíduo disposto ou tempo de degradação (apresentado na Tabela 1);

b) Caminhos ambientais percorridos pelo contaminante: Podem ser subterrâneos ou superficiais. Os subterrâneos são, basicamente, influenciados pela permeabilidade do solo e pela espessura da camada de solo acima do nível freático. Os caminhos superficiais sofrem influência da topografia, que proporciona locais com possibilidade de alagamento ou de escoamento superficial. Quando há presença de alagamentos, o lixiviado estagnado tende tanto se infiltrar quanto a evaporar, o que contamina o solo e o ar. Quando há escoamento superficial, dependendo da inclinação do talude, pode ocorrer erosão causada pelo impacto do líquido no solo, com risco de dano à camada de cobertura, geralmente mal feita, bem como o alcance até grandes distâncias. Ambas as situações podem ser atenuadas dependendo da sua posição em relação ao aterro. Quando o balanço hídrico é negativo, ou seja, o volume de água evaporada é maior do que a água precipitada que potencialmente se infiltra no solo, o lixiviado de um aterro de RSU é composto apenas de seu chorume, ou seja, da fração da umidade natural proveniente do próprio RSU e do processo de biodegradação.

c) Sujeito potencialmente exposto: Os seres humanos (ou animais) que ocupam o entorno do aterro bem como recursos naturais.

Na Figura 1 é apresentado o organograma da metodologia empregada na construção das matrizes.

\section{RESULTADOS}

As Tabelas 1, 2, 3, 4A e 4B apresentam as matrizes construídas. Em cada uma das matrizes, os valores entre parênteses foram considerados aceitáveis, os valores entre colchetes foram considerados altos de acordo com a sensibilidade de alguns especialistas nos temas.

\section{Matriz de avaliação da produção de chorume - fonte}

Na Tabela 1, apesar de as divisōes de fases em que se encontra o processo de estabilização do RSU não terem limites de tempo rigorosos, considerou-se três faixas principais:

Até 5 anos: Os poluentes geralmente alcançam valores máximos durante os primeiros anos de operação do aterro (2-3 anos) e decrescem gra-

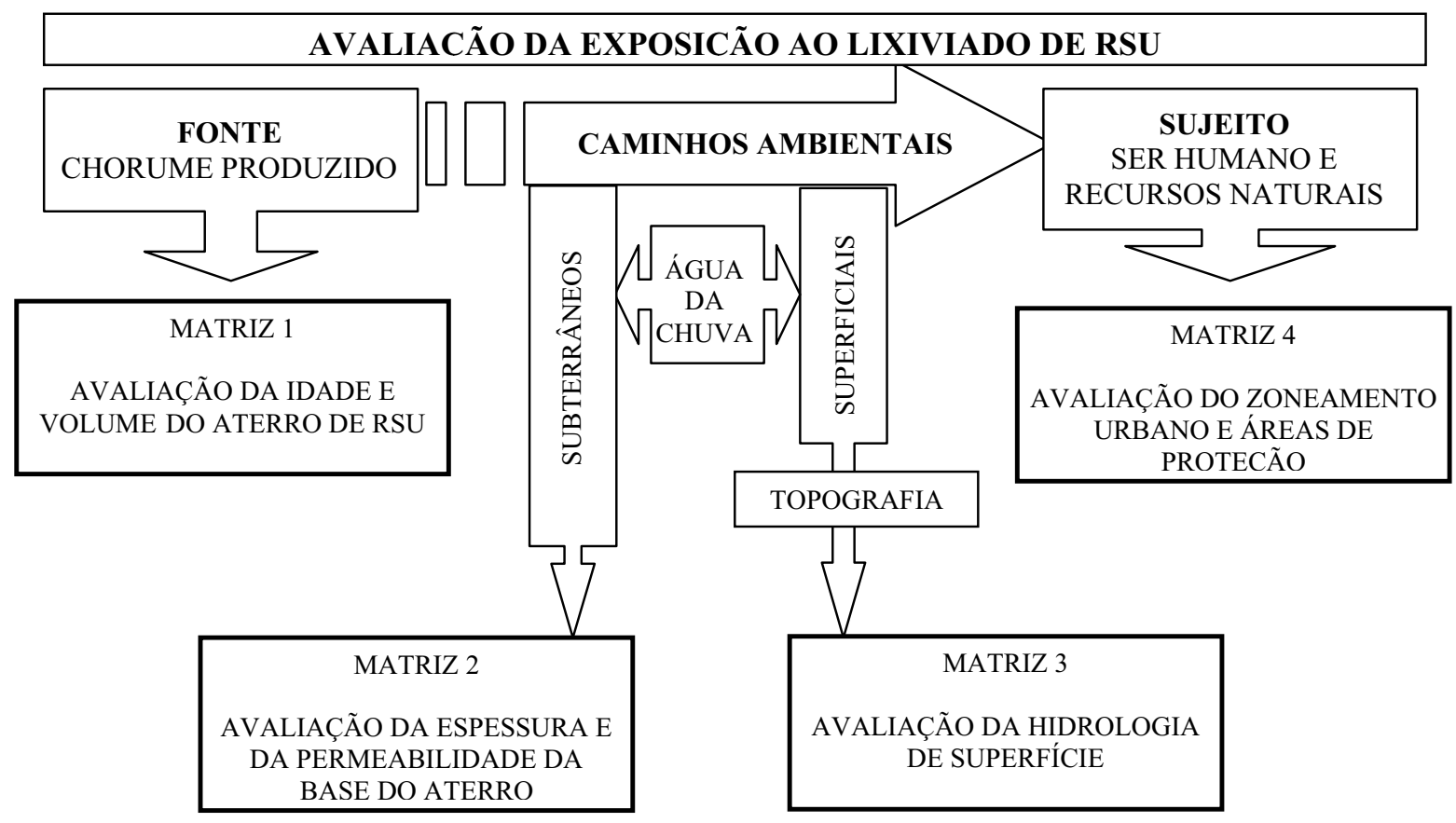

Figura I- Organograma da metodologia usada na construção das matrizes 
dualmente durante os anos seguintes. (IPT/Cempre, 2000 e Andreotolla et al, 1997);

5 a 30 anos: A velocidade da decomposição do resíduo, depois que chega ao seu máximo, baixa lentamente continuando até 25 anos ou mais (Tchobanoglous, 1997).

Mais do que 30 anos: $\mathrm{O}$ processo de estabilização do RSU encontra-se bastante evoluído, o que influência na diminuição da produção dos efluentes.

\section{Matriz de avaliação da base do aterro - caminhos ambientais subterrâneos}

Na Tabela 2 são consideradas três faixas de valores para permeabilidade do solo, sugeridos nas normas brasileiras. Para baixa permeabilidade foi adotado o valor de $\mathrm{K} \leq 1 \mathrm{E}^{-6} \mathrm{~cm} / \mathrm{s}$, a média permeabilidade compreende o intervalo entre $1 \mathrm{E}^{-6}<\mathrm{K}<5 \mathrm{E}^{-4} \mathrm{~cm} / \mathrm{s}$, e a alta permeabilidade é considerada quando $\mathrm{K} \geq 5 \mathrm{E}^{-4} \mathrm{~cm} / \mathrm{s}$.

\section{Matriz de avaliação do alcance do lixiviado - caminhos ambientais superficiais}

$\mathrm{Na}$ Tabela 3 a atribuição de valores foi feita de zero a 20 , sob o critério qualitativo de modo que áreas que recebem o mesmo valor apresentam o mesmo potencial de risco. As piores condiçōes são as com balanço hídrico positivo, que receberam valores entre 10 e 20 . As condições topográficas similares, em regiōes com o balanço hídrico negativo, receberam 10 pontos a menos do que as respectivas com o balanço hídrico positivo.

Região Inundável (Figura 2) é aquela em que o balanço hídrico é positivo em alguma época do ano e as características topográficas possibilitam condiçôes de alagamento.

A " Quando isto ocorre a montante do aterro, a infiltração tende a servir como recarga do aqüífero com água não contaminada, o que, a prin- cípio pode ser considerado um aspecto positivo. No entanto há a possibilidade de ocorrerem fluxos preferenciais para o interior do aterro, o que pode aumentar a sua umidade.

B " Quando a situação ocorre sobre o aterro, a infiltração tende a aumentar sua umidade e conseqüentemente a geração de lixiviado.

C " Quando ocorre à jusante do aterro, o local alagado pode estar contaminado por lixiviado. Neste caso, o líquido poderá infiltrar causando contaminação da superfície do solo até atingir o aquiífero ou evaporar, o que se apresenta como um aspecto bastante negativo.

Região Possivelmente Inundável (Figura 3) é idêntica á situação anterior - Região inundável - porém, o balanço hídrico apresenta-se negativo, o que torna improvável a ocorrência de inundação. Como há sempre a possibilidade de uma modificação climática, o risco não pode ser descartado. Os itens $\mathrm{D}, \mathrm{E}$, $\mathrm{F}$, são similares aos $\mathrm{A}, \mathrm{B}, \mathrm{C}$ em relação
Tabela I - Matriz de avaliação da produção de chorume

\begin{tabular}{cccc}
\hline Volume $\mathrm{m}^{3}$ & \multicolumn{3}{c}{ Idade do RSU (anos) } \\
& Até 5 & 5 a 30 & Mais de 30 \\
\hline$<10.000$ & $(3)$ & $(2)$ & $(1)$ \\
$10.000-30.000$ & $(6)$ & $(5)$ & $(4)$ \\
$30.000-50.000$ & 9 & 8 & $(7)$ \\
$50.000-70.000$ & 12 & 11 & 10 \\
$70.000-90.000$ & 15 & 14 & 13 \\
$90.000-110.000$ & 18 & 17 & 16 \\
$110.000-130.000$ & {$[21]$} & {$[20]$} & 19 \\
$130.000-150.000$ & {$[24]$} & {$[23]$} & {$[22]$} \\
$150.000-170.000$ & {$[27]$} & {$[26]$} & {$[25]$} \\
$>170.000$ & {$[30]$} & {$[29]$} & {$[28]$} \\
\hline
\end{tabular}

Tabela 2- Matriz de avaliação da base do aterro

\begin{tabular}{cccc}
\hline $\begin{array}{c}\text { Espessura náo } \\
\text { saturada }(\mathrm{m})\end{array}$ & \multicolumn{3}{c}{ Permeabilidade do Solo $(\mathrm{cm} / \mathrm{s})$} \\
$\mathrm{k}<1 \mathrm{E}^{-6}$ & $5 \mathrm{E}^{-4}>\mathrm{k}>1 \mathrm{E}^{-6}$ & $\mathrm{k}>5 \mathrm{E}^{-4}$ \\
\hline$>10$ & $(1)$ & 11 & {$[21]$} \\
5,0 a 10 & $(2)$ & 12 & {$[22]$} \\
4,0 a 5,0 & $(3)$ & 13 & {$[23]$} \\
3,0 a 4,0 & $(4)$ & 14 & {$[24]$} \\
2,5 a 3,0 & 5 & {$[15]$} & {$[25]$} \\
2,0 a 2,5 & 6 & {$[16]$} & {$[26]$} \\
1,5 a 2,0 & 7 & {$[17]$} & {$[27]$} \\
1,0 a 1,5 & 8 & {$[18]$} & {$[28]$} \\
0,5 a 1,0 & 9 & {$[19]$} & {$[29]$} \\
$<0,5$ & 10 & {$[20]$} & {$[30]$} \\
\hline
\end{tabular}

Tabela 3 - Matriz de avaliação da topografia e da pluviosidade

\begin{tabular}{|c|c|c|c|}
\hline \multirow[t]{2}{*}{ Característica } & \multicolumn{3}{|c|}{ Localização em relação ao aterro } \\
\hline & Jusante & Sobre & Montante \\
\hline Região inundável: TP / BH+ & {$[18]$} & {$[20]$} & {$[12]$} \\
\hline Região possivelmente inundável: TP / BH- & 8 & 10 & $(2)$ \\
\hline Região sujeita a escoamento superficial de alta energia: TP / BH+ & [14] & [16] & {$[20]$} \\
\hline Região com possível escoamento superficial de alta energia: TP / BH- & $(4)$ & 6 & 10 \\
\hline Região protegida contra inundação ou escoamento superficial, com $\mathrm{BH}+$ & 10 & 10 & 10 \\
\hline Região protegida contra inundação ou escoamento superficial com BH- & (0) & (0) & $(0)$ \\
\hline
\end{tabular}

BH - Balanço hídrico (+ positivo / - negativo)

TP - Topografia propícia 
à topografia, diferindo pelo balanço hídrico, que se apresenta negativo e não possibilita a presença de água.

Região Sujeita ao Escoamento Superficial (Figura 4) é aquela em que o balanço hídrico é positivo em alguma época do ano e as características topográficas de declividade possibilitam o forte escoamento superficial. Esta situação topográfica induz a erosão da superfície, e possibilita o carreamento de sedimentos e transporte de líquido até distancias relativamente grandes.

G " Quando isto ocorre a montante do aterro, poderá ser observado um aumento de água atingindo o aterro, o que contribui para uma maior formação de lixiviado, o que é um aspecto negativo.

$\mathrm{H}$ " Quando isto ocorre sobre o aterro, pode ocorrer aumento da erosão na camada superficial do aterro, o que é um aspecto negativo.

I " Quando isso ocorre à jusante, o escoamento superficial que pode estar contaminado pelo lixiviado, tenderá a atingir mais rápido, maiores distâncias, o que também é um aspecto negativo.

Região Sujeita ao Possivel Escoamento Superficial (Figura 5) é idêntica á situação anterior - Região Sujeita ao Escoamento Superficial - porém, o balanço hídrico apresenta-se negativo, o que torna improvável a ocorrência de inundação. Aquela em que as condições topográficas permitem o escoamento. Este, porém, é improvável porque o balanço hídrico apresenta-se negativo por todo o ano. As condições são semelhantes às do item anterior, caso ocorra presença de água. Os itens J, K, L, são similares aos $\mathrm{G}, \mathrm{H}, \mathrm{I}$, em relação à topografia, diferindo pelo balanço hídrico negativo, que impossibilita a ocorrência de escoamento superficial.

Região Protegida Contra Inundação ou Forte Escoamento Superficial trata-se de área em que as condições topográficas impossibilitam o alagamento ou escoamento superficial, mesmo com alta presença de água. Quando se trata do entorno do aterro tanto a montante quanto à jusante, haverá muito pouca contribuição de água à área.

\section{Matriz de avaliação do entorno do aterro - sujeito}

As Tabelas 4 A e B apresentam a avaliação das características do zoneamento urbano nas proximidades do aterro.
$\mathrm{Na}$ matriz de avaliação do uso do solo (Tabela $4 \mathrm{~A}$ ), são tratadas a proximidade da ocupação e o tipo de população sujeita ao contato com os efluentes do aterro. Seu objetivo é pontuar a capacidade dos efluentes atingirem os habitantes expostos da região. Foram considerados três tipos de uso, que se relacionam ao tempo de permanência das pessoas no local. A proximidade do aterro aos núcleos urbanos propicia, em diversos níveis, a exposição antrópica aos efluentes do resíduo. Em relação ao lixiviado, o contato pode se dar tanto pela contaminação das águas subterrâneas e superficiais e do solo, como por via aérea, pelo ar contaminado pela evaporação do efluente. A água contaminada pode ser utilizada por animais domésticos e de criação para abate, rega de plantas, inclusive hortaliças, bem como pelo contato direto por meio de poços e mesmo para o lazer. O solo contaminado superficialmente, quando ocorre afloramento de lixiviado, pode estar sendo utilizado para hortas, jardins, áreas de lazer entre outros. Aparentemente, a concentração de pessoas em um determinado espaço acelera os processos de degradação ambiental, e isso costuma ser acentuado em núcleos residenciais de baixa renda. A precariedade sanitária que as instalaçôes costumam apresentar gera maior suscetibilidade às influên-

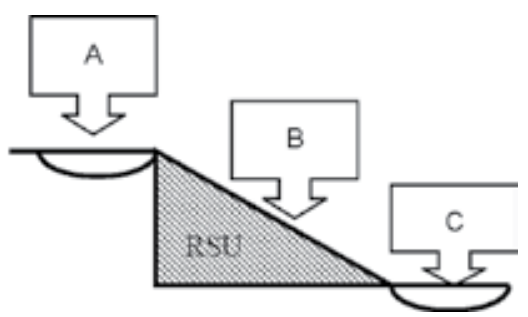

Figura 2 - Esquema das alternativas da categoria região inundável

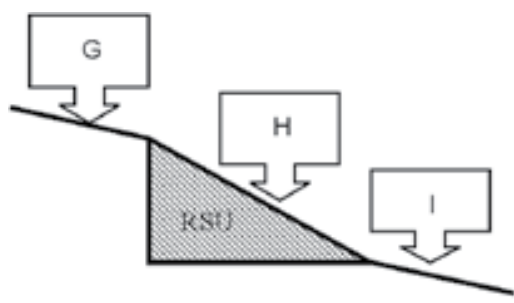

Figura 4 - Esquema das alternativas da categoria região sujeita ao escoamento superficial com fluxo de alta energia cias do contato com o aterro de RSU. Nestes locais é usual haver negligência em relação a autoproteção e à proteção ambiental tanto por ignorância e falta de recursos por parte dos moradores, como pela dificuldade de fiscalização por parte do poder público. Quando a área residencial apresenta-se com habitaçôes de baixa renda adiciona-se 1 ponto na pontuação equivalente.

$\mathrm{Na}$ matriz de avaliação dos recursos naturais potencialmente afetados (Tabela 4B), os aspectos considerados são relacionados à proximidade do aterro a áreas ambientais protegidas ou corpos hídricos. Segundo a Portaria Minter no. 124 de 20 de agosto de 1980 não podem ser instalados empreendimentos potencialmente poluentes a menos de $200 \mathrm{~m}$ de corpos d'água. Estão sendo consideradas Zonas de Preservação Ambiental as regiōes urbanas que, por suas características e pela tipicidade da vegetação, destinam-se à preservação e à recuperação de ecossistemas, visando garantir espaço para a manutenção da diversidade das espécies e propiciar refúgio à fauna assim como proteger as nascentes e as cabeceiras de cursos d'água. São consideradas Zonas de Proteção, as regiōes sujeitas a critérios urbanísticos especiais, que determinam a proteção ambiental de áreas, tendo em vista o interesse público na proteção.

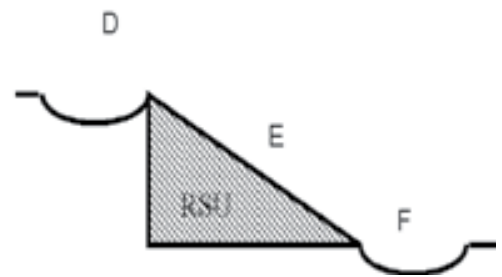

Figura 3 - Esquema das alternativas da categoria região possivelmente inundável

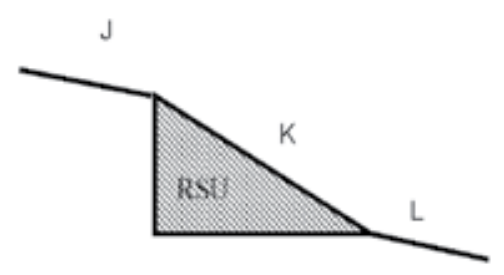

Figura 5 - Esquema das alternativas da categoria região sujeita ao possível escoamento superficial com fluxo de alta energia 
Tabela 4- Matriz 4A e 4B, de avaliação do sujeito potencialmente atingido

\begin{tabular}{|c|c|c|c|c|c|c|}
\hline \multirow[t]{3}{*}{ Distância (m) } & \multicolumn{3}{|c|}{ (A) Urbano } & \multicolumn{3}{|c|}{ (B) Ambiental } \\
\hline & \multicolumn{3}{|c|}{ Uso do solo urbano } & \multicolumn{3}{|c|}{ Recursos naturais potencialmente afetados } \\
\hline & Agrícola & $\begin{array}{c}\text { Residencial/ } \\
\text { parques/jardins }\end{array}$ & $\begin{array}{l}\text { Comercial/ } \\
\text { industrial/serviços }\end{array}$ & $\begin{array}{c}\text { Zonas de preservação } \\
\text { ambiental }\end{array}$ & $\begin{array}{l}\text { Corpos } \\
\text { hídricos }\end{array}$ & $\begin{array}{l}\text { Zonas de } \\
\text { proteção }\end{array}$ \\
\hline$<100$ & {$[20]$} & {$[19(+1)]$} & {$[18]$} & {$[20]$} & [19] & {$[18]$} \\
\hline De 101 a 200 & {$[17]$} & {$[16(+1)]$} & {$[15]$} & {$[17]$} & {$[16]$} & {$[15]$} \\
\hline De 201 a 400 & 14 & $13(+1)$ & 12 & 14 & 13 & 12 \\
\hline De 401 a 600 & 11 & $10(+1)$ & 9 & 11 & 10 & 9 \\
\hline De 601 a 800 & 8 & $7(+1)$ & 6 & 8 & 7 & 6 \\
\hline De 801 a 1.000 & (5) & $(4(+1))$ & (3) & (5) & (4) & (3) \\
\hline$>1.000$ & (2) & $(1(+1))$ & $(0)$ & (2) & (1) & $(0)$ \\
\hline
\end{tabular}

\section{DISCUSSÃO}

Os valores foram distribuídos nas matrizes de modo que a matriz 1 , referente à produção de chorume, e a matriz 2 , referente à capacidade do lixiviado atingir o aqüífero, contribuem cada uma com $30 \%$ do total da pontuação, totalizando $60 \%$. Estas matrizes receberam maior peso pela maior dificuldade relativa de se solucionar as questôes envolvidas. A matriz 3, referente às condiçôes climáticas que influenciam a geração de efluente e as condiçôes topográficas que influenciam a capacidade de drenagem natural do líquido aflorado ou escoado superficialmente, contribui com $20 \%$ do total da pontuação. A matriz 4 $(A+B)$, referentes aos recursos naturais e população potencialmente atingida pelo contato com o efluente, contribui com $20 \%$ do total da pontuação. A pontuação total será: Matriz $1+\mathrm{Ma}$ triz $2+$ (máximo valor encontrado na Matriz 3) + (máximo valor encontrado nas matrizes $4 \mathrm{~A}+4 \mathrm{~B}$ )

$\mathrm{O}$ resultado classifica a área segundo três categorias relacionadas aos diferentes níveis de cuidados ambientais pós-fechamento. As faixas de pontuação estabelecidas foram limitadas a partir da soma dos valores considerados mínimos, máximos e intermediários, identificados em cada uma das matrizes por algarismos entre parênteses, normais e entre colchetes respectivamente. A avaliação inicial do risco de exposição do lixiviado deve ser confirmada por meio de analises das águas subterrâneas e, a partir daí, determinados os procedimentos de fechamento do aterro, com remediação se necessário.
Até 20 pontos - BAIXO risco de exposição ao lixiviado. Sua confirmação é feita por meio de análises químicas das águas subterrâneas, cujos resultados devem apresentar teores que não excedam às referências da região. A área deverá passar por um monitoramento desenvolvido em duas fases:

a) Durante o $1^{\circ}$ ano é proposto um monitoramento trimestral, para que sejam identificados períodos críticos em relação a eventual presença de contaminação.

b) Depois disso o monitoramento passa a ser anual durante 5 anos.

Caso não haja alteração provocada pelo lixiviado do RSU no aqüífero superficial, a área pode ser considerada ambientalmente saudável em relação ao risco de exposição ao lixiviado.

De 21 a 60 pontos - MÉDIO risco de exposição ao lixiviado. A confirmação é feita por meio de análises químicas das águas subterrâneas, cujos resultados esperados apresentam teores mais elevados do que as referências da região. Neste caso são necessárias açôes visando à proteção ambiental, seguidas de um monitoramento das águas subterrâneas dividido em 3 fases.

a) Monitoramento trimestral durante 1 ano, para que sejam identificados períodos críticos em relação à contaminação do aqüífero.

b) $\mathrm{O}$ monitoramento semestral até que os resultados apresentem valores que não excedam as referências da região.

c) Depois disso o monitoramento passa a ser anual durante 5 anos.

De 61 a 100 pontos - ALTO risco de exposição ao lixiviado. A confirmação é feita por meio de análises químicas das águas subterrâneas, cujos resultados esperados apresentam teores iguais ou mais elevados do que os Valores Máximos Permitidos para as substâncias, segundo a portaria 518 do Ministério da Saúde. São necessárias ações urgentes visando à proteção ambiental. Depois disso deverá ser desenvolvido um monitoramento das águas subterrâneas, dividido em 3 fases.

a) Monitoramento trimestral das águas subterrâneas com análises químicas, até que os resultados apresentem valores de concentração de contaminantes mais baixos do que os Valores Máximos Permitidos para as substâncias pela portaria 518 do Ministério da Saúde para as substâncias tóxicas presentes no lixiviado.

b) Idem aos itens b e c da categoria (MÉDIO risco de exposição ao lixiviado).

\section{CONCLUSÕES}

Depois de feita a avaliação inicial da área, diagnosticado o passivo ambiental, e obtidas informações sobre o risco de exposição ao lixiviado e a influência que este exerce no seu entorno, é importante considerar o nível de recuperação necessário. Normalmente são necessários cuidados como instalação de sistema de drenagem superficial, remoção de resíduos próximos a cursos d'água, quando o aterro está situado próximo a áreas alagadas, construção de sistemas de drenagem de lixiviado, instalação de drenos de gás, retaludamento e cobertura dos resíduos.

Deve-se considerar que áreas que foram usadas para disposição de resíduos, depois de encerradas, muitas vezes 
tornam-se locais de potencial interesse para ocupação por população de baixa renda. Sabendo-se que esses antigos aterros podem continuar produzindo efluentes e contaminando o entorno durante muitos anos, é importante que não sejam simplesmente abandonados, mas que tenham um destino adequado ao contexto urbano, podendo ser fiscalizados para evitar sua ocupação irregular.

Parte-se do principio de que aterros de RSU costumam apresentar características similares, conforme verificado no programa de controle de áreas contaminadas "Superfund", da USEPA (1997). Desta forma, tanto a identificação do passivo ambiental quanto a adoção de medidas de remediação e monitoramento podem ser presumidos, o que reduz o tempo e o custo das investigaçōes detalhadas. Assim, o método de avaliação aqui proposto visa contribuir ao estabelecimento de critérios para a avaliação do risco de exposição ao lixiviado e remediação da área visando sua reintegração urbana e, conseqüentemente, otimizando tempo e recursos financeiros.

\section{AGRADECIMENTOS}

Os autores agradecem a FAPERJ e ao CNPq pelo apoio.

\section{REFERÊNCIAS}

ANDREOTTOLA G. \& CANNAS P. Chemical and biological characteristics of landfill leachate in Landfilling of waste: Leachate. T.H. Christensen, R. Cossu e R. Stegman (editors), pp $65-88.1977$.

IPT/CEMPRE. Lixo Municipal: manual de gerenciamento integrado. $1^{\mathrm{a}} \mathrm{ed}$. São Paulo: Instituto de Pesquisa Tecnológicas/IPT. 2000.

MINISTÉRIO DA SAÚDE. Portaria n 518 , de 25 de março de 2004

NARDOCCI, A. C. Risco como instrumento de gestão ambiental. Tese de doutorado. Faculdade de Saúde Pública USP. São Paulo-SP. 135p. 1999.

PORTARIA MINTER no 124 de 20 de agosto de 1980

UNITED STATES ENVIRONMENTAL PROTECTION AGENCY - USEPA. Landfill Presumptive Remedy Saves Time and Cost. Office of Solid Waste and Emergency Response EPA540/F-96/017. 1977.

TCHOBANOGLOUS, G., THEISEN, H.; VIGIL, S. Gestion integral dos resíduos sólidos. 1 ed. Madri: McGraw-Hill, Inc, v(s).1-2, 1106p. (em Espanhol). 1994.
Endereço para correspondência:

Adriana Soares de Schueler Universidade Federal do Rio de Janeiro - UFRJ

Programa de Engenharia Civil

Laboratório de Geotecnia

Prédio anexo

Cidade Universitária - Centro de

Tecnologia Illa do Fundão

Caixa Postal 68506

2 I 945-970 Rio de Janeiro - RJ -

Brasil

Tel.: (2I) 2562-7775 - 93I3-0444

Fax: (2I) 2290-I 730 R. 202

E-mail: schueler.a@gmail.com 